\title{
Model of Integrated Management System for Quality and Food Safety of Biscuit Products
}

\author{
Marieta Stefanova \\ Department of Commodity Science, Faculty of Economics, Varna University of Economics, bul. Knyaz Boris I № 77, Varna BG-9002, \\ Bulgaria
}

\begin{abstract}
The revised version of ISO 9001:2015 places a demand before many food producers to face the problem of updating the old or developing new food quality and safety management systems. In order to help the organizations in this endeavor, this paper presents a model for planning and implementation of IMS (integrated management system) for quality and food safety, using the example of biscuit products manufacturing, and explains its conception. The integrative approach is based on the synergetic effect between the mutually related business processes. It has been established that the introduction of the model can help the biscuit producers in efficiently addressing such challenges as limited resources, increasing competition, as well as higher expectations of customers and other stakeholders.
\end{abstract}

Key words: Food safety, quality management, ISO 9001:2015, biscuit products.

\section{Introduction}

The challenges faced by food producers such as limited resources, increasing competition, as well as higher expectations of customers and other stakeholders regardless of their market [1] can be efficiently addressed by the implementation of an IMS (integrated management system) for product safety and quality. In order to meet these global needs and expectations, an integrated model should be created for the development and implementation of a system, which can be applied in the management of food establishments and which can cover all standards, required to be met [2]. The implementation of IMS is an efficient instrument adopted in the practice, which the companies can use in order to bring their activities in optimum compliance with the current requirements in the ever changing competitive environment [3]. The integration of the series ISO 9001 and the standards for food safety management have been successfully applied by food companies. The latest completely different version of ISO

Corresponding author: Marieta Stefanova, Ph.D. student, research fields: food quality and safety management system.
9001:2015 [4] published two years ago imposed radical changes in all systems based on this standard. Furthermore, it is to be regretted that scientific publications do not give adequate analysis of the problem how we should create new integrated systems for quality and food safety based on this latest edition of the standard.

Currently, most of the confectionery and pastry plants have already introduced management systems, adapting to the market environment and the new economic conditions. The survival and the prosperity of the biscuit manufacturing plants in the conditions of strong international competition cannot be guaranteed without the development and certification of a modern integrated management system, based on the process approach. In this connection, modern biscuit manufacturers have to develop a modernized quality management system in accordance with ISO 9001:2015, based both on private standards, as required by the trade chains $[5,6]$ and on standards for food safety management [7]. Making simultaneous use of the three elements will allow the business to deal more efficiently with the safety and the quality of products in a dynamic environment. 
The benefits from the introduction and certification of the integrated system for quality management can be found in several areas. In the first place, the improvement of the reputation of the manufacturer and opening of new opportunities for entering new markets [8-12]. In the second place, reduction of costs as result of reducing disparities and ensuring compliance with the legislative and other requirements related to safety and quality $[8,12-14]$. In the third place, possibility to achieve optimization by applying a common management approach to several standards [15]. And in the fourth place, increasing flexibility and efficiency by means of integrated solutions, which include the requirements of multiple standards [9, 16-18].

The negatives from the introduction of the integrated management system can be found in several areas: In the first place, the difficulties arising from the introduction, analysis and processing of a large amount of information, which has to be integrated [19-22]. In the second place, increasing of costs related to certification and purchasing of new equipment $[23,24]$. And thirdly, the need to train employees for meeting a number of requirements [20, $21,25]$.

The application of a process approach in creating management systems is a necessary precondition for its success. The scientific publications show a lot of different models, which can be implemented. The model of the BSI (British Standards Institution) with its latest version PAS 99:2012 [26] has found the broadest application and reference (Fig. 1). This model does not have a specific application, as it only defines a common structure, which can be followed by all standards of management systems.

The model used in this research is based on the common structure indicated in PAS 99:2012 (Fig. 1), and is specifically oriented towards the development of an integrated management system for quality and food safety using the example of biscuit products manufacturing. The analysis of scientific publications

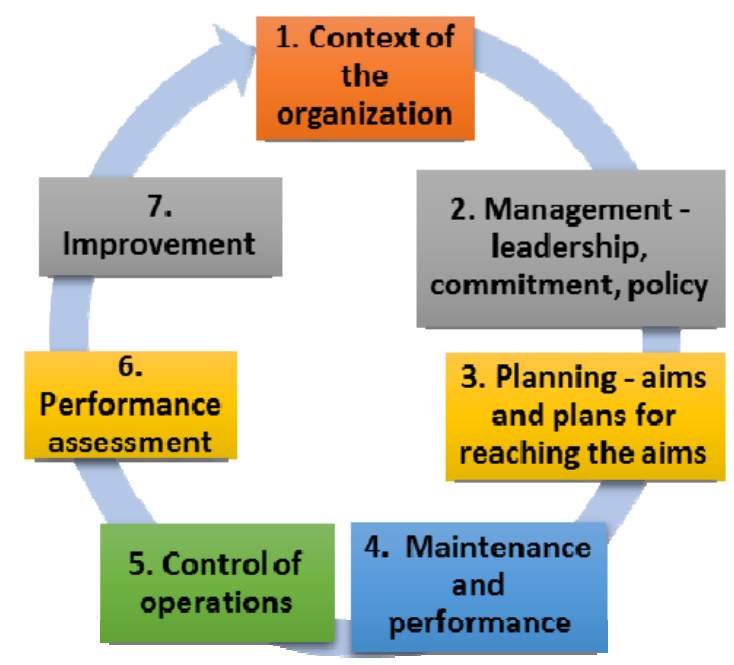

Fig. 1 Model of IMS in accordance with PAS 99:2012.

identifies the need to integrate the whole body of requirements in an innovative management system for food quality and safety within the framework of the current model shown in Fig. 1.

The numerous opinions and approaches on integrated systems modeling found in scientific publications give us reasons to maintain that there is no adequate research of models for creating integrated systems specifically oriented towards the quality and safety of biscuit products, including also the requirements of ISO 9001:2015.

The term IMS used in the present research is a management system, which combines a food safety management system with a quality management system.

The purpose of this research is to define a model for creating an integrated management system for quality and food safety using the example of biscuit products manufacturing.

\section{Materials and Methods}

This research was carried out in two biscuit manufacturing plants in Bulgaria. The production of the plants is sold in 37 states, and the list of product range includes 180 different items manufactured on 11 production lines.

The research covers one calendar year from December 2015 until December 2016. The data from 
the research were collected through observation and analysis of the different stages of the process starting with receiving the materials and ending with the shipment of the finished products. Additional information was obtained also from internal compliance audits.

The main method used in the conformity assessment of the applied method was the audit by an accredited body for conformity assessment of food quality and safety management systems.

The internationally recognized accreditation authority for accreditation of conformity assessment bodies is the IAF (International Accreditation Forum), Inc. The bodies accredited by IAF have proven their competence to carry out this activity within their scope of accreditation.

The conformity assessment of the system was carried out by ISACert B.V., which performs conformity audits along the whole food supply chain. In its capacity of certification body, ISACert B.V. has been accredited by the Dutch Accreditation Council (RvA), which is a member of IAF and the ASI (Accreditation Services International) and recognized by the owners of standard schemes for auditing and certification (Certification under No. C062; No. C241).

Following the observations on the interaction between processes and quality and safety management we made an analysis which cannot be interpreted by quantitative methods. We carried out a qualitative research based on Patton's methodology [27].

Scope of the integration model and subject of the research are the main management processes for the quality and safety of biscuit products. Manufacturing of biscuit products includes processes which can be defined, measured and improved. These processes interact in order to achieve results in accordance with the aims and objectives of the organization. Certain processes can be critically important for the achievement of the aims and should be efficiently monitored, in order to minimize the risk of failure.
The management system created according to the model covers all processes, which consist of interrelated activities and which transform the input elements into output. The quality management processes to be covered by the integrated system model using the example of biscuits are as follows:

Management processes in manufacturing biscuit products:

- Processes for conformity management meeting the requirements for quality management systems-ISO 9001:2015 [4].

- Processes for conformity management meeting the requirements for food safety systems ISO 22000 [7].

- Processes for conformity management meeting the requirements for the trade chains BRC Food 7 [6], IFS Food 6 [5].

\section{Results and Analysis}

The main purpose of the IMS introduction is to achieve on the one hand, the compliance of the product with the statutory accepted standards in the industry, and on the other hand, to achieve customer satisfaction. The implementation of IMS is aimed to ensure manufacturing of products which meet the specifications and requirements. The introduction of food safety standards provides a method of preventing nutrition incidents and guarantees the safety of the product for human consumption.

The integration is planned and carried out in a structured way according to the stages indicated in Fig. 1. Prior to establishing the integration model, it is necessary to carry out a detailed analysis of the individual requirements to the standards applicable for integration as well as their compatibility with the processes and activities already in place.

\subsection{Stage 1. Preparation for the Implementation of Activities}

(1) The first stage in designing the system started by defining the context of the organization. Analysis 


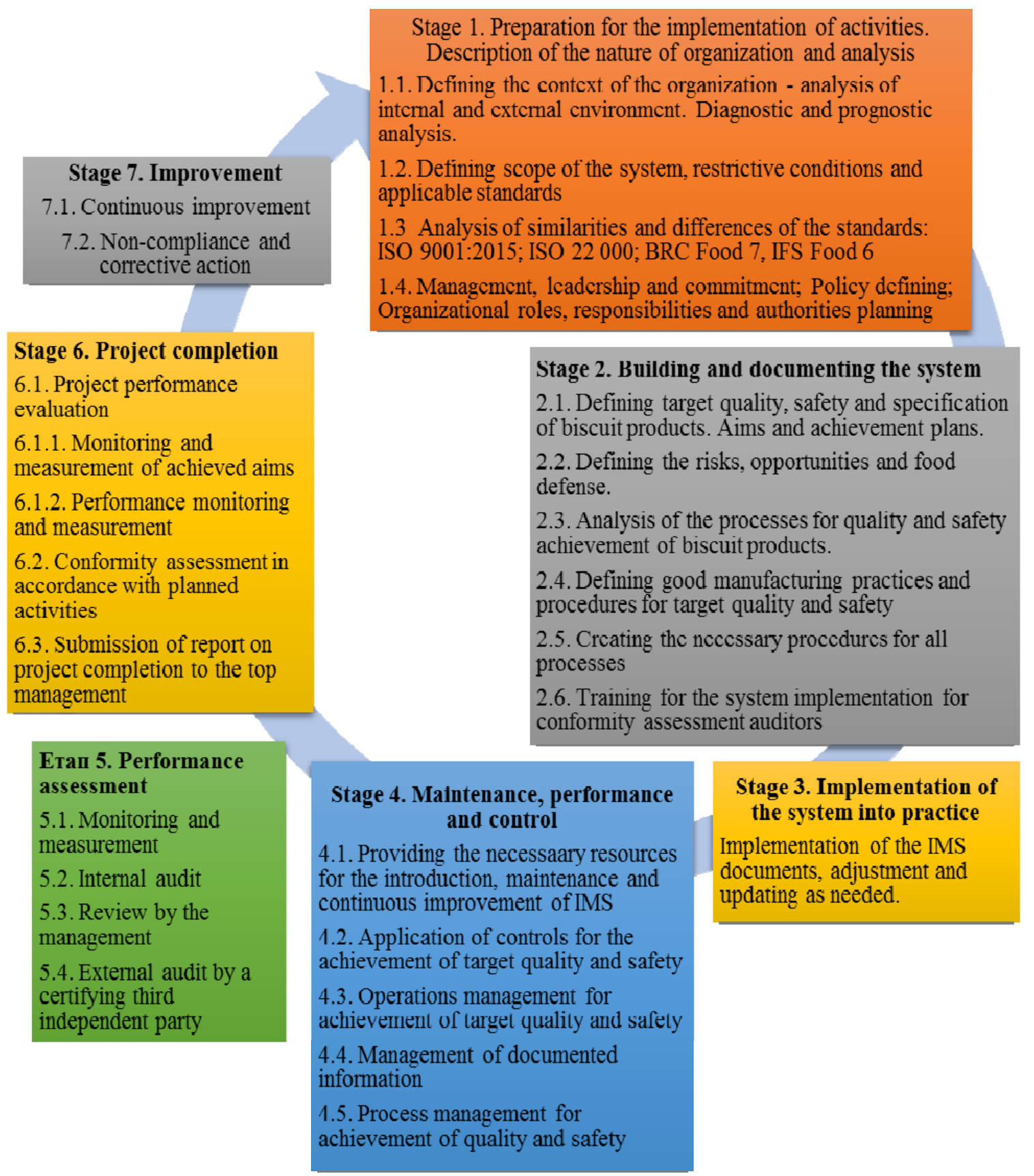

Fig. 2 Model for designing and introduction of IMS.

was carried out for the identification, evaluation and forecasting the changes in the political, economic, social, ecological and legislative environment on the background of manufacturing biscuit products, which have an impact on the whole industry. At this stage, the factors influencing the applicability of the model were also evaluated, including the time restrictions.
Following an analysis of the significant factors having an effect on both the organization and the feasibility of the model, a plan was prepared to minimize the risks of the internal and external environment.

(2) The scope of the system was defined: manufacturing, storage and distribution of biscuit products in accordance with the standards applicable 
to the system: ISO 9001:2015, ISO 22 000:2006, IFS Food; BRC Food.

(3) At this stage, we carried out also a comparative analysis of similarities and differences between legislative requirements and the requirements for the quality management in accordance with ISO 9001:2015 and food safety specified in ISO 22 000:2006, IFS Food; BRC Food. We summarized the data obtained from comparing the requirements by identifying the common elements and the respective differences, and carried out compatibility assessment finding possibilities for the integration of these requirements.

(4) Defining and management of the necessary leadership and commitment. The commitment and the active participation of the top management are a necessary precondition for the development, implementation and maintenance of effective and efficient integrated management system, and for its continuous improvement. At this stage of the process we defined the responsibilities of the team members working for the model implementation. The management of the organization updated the standard according to the new requirements and defined new policy for the quality and safety of foodstuffs. The main aims and objectives of the developed and implemented integrated system were also defined.

\subsection{Stage 2. Building and Documenting the System}

(1) Defining the target quality, safety and specification of biscuit products. At this stage we defined the target quality, safety and specification of biscuit products. The target indicators for quality were established for the respective levels and processes across the whole organization for the implementation of approved policies, product and process requirements, as well as for the improvement of IMS and of productivity.

(2) Defining the risks, opportunities and food defense. At this stage in the process we created a set of procedures for risk and opportunity management as follows:

PIMS (procedure integrated management system) 610-01, regulating the actions for dealing with risks and opportunities, which are part of the decision making on all organizational levels and one of the mechanisms for improving the processes and the management system.

PIMS 610-02, regulating the rules and requirements concerning the minimization of the risk that the foods produced in all establishments are controlled by the company and that they will not become subject of falsification or other malicious, criminal or terrorist actions.

PIMS 610-03, regulating the preparation for the performance of the main processes related to risk analysis and identifying the critical control points in the management system for the foodstuffs in the company.

PIMS 610-04, which regulates the processes of identification and analysis of hazards, defining the hazards to be controlled and the level of control required to ensure the safety of products.

PIMS 610-05, which determines the development and introduction of HACCP plans as part of the management system for the safety of foodstuffs.

(3) Analysis of the processes for the achievement of quality and safety. While planning the processes in the system, we took into consideration that the integrity of IMS should be maintained in the course of planning and implementing the relevant changes. The planning of changes included reallocation of responsibilities and competences for each activity.

(4) Defining good manufacturing practices. The Prerequisite Programs ensure control on the factors related to working environment and the conditions for manufacturing the products. In this sense, their application does not allow, eliminate or reduce to an acceptable level all risks of food contamination. In order to ensure the safety of the products, we defined the necessary requirements, set out in the Prerequisite Programs and the procedures shown in Fig. 2. We 
created also the operating instructions containing detailed and specific presentation of the sequence for the implementation of the determined processes or operations, regulated in the procedures.

(5) Creating the necessary procedures for all processes, indicated with their names in Fig. 2. The procedures are part of the documentation pertaining to the Integrated Management System, used for overall planning and management of the processes related to food quality and safety. They regulate the subject and the scope of the different processes, which have impact on the food quality and safety, the approved rules and methods for their implementation, the obligations, competence and relations of the personnel, who manages, carries out, inspects or supervises these processes and the necessary relevant documentation. A total of 26 procedures have been regulated, the names of which are specified in Fig. 2.

(6) Training for the implementation of the system, including auditors for conformity assessment. The main objective of the training shall be ensuring the necessary knowledge and skills of the persons involved with the IMS activities.

\subsection{Stage 3. Implementation of the Model, Adjustment and Updating as Needed}

The implementation of the model resulted in applying practically the rules planned for the system and at the same time allowed us to verify the conformity between the designed and the actual operating process. The implementation of the system included making a list of all divisions where the system was to be put into service and stage by stage distribution of documents. The implementation was done in the two production facilities of the company. During the implementation process we kept all forms and records required by IMS, grouping them in files. The traceability of the entered the documentation was checked. The technical infrastructure for the implementation of the new processes was ensured. The internal rules and procedures were updated at the place of use. Obsolete and invalid copies of documents were removed. Corrections and updating were made in the documentation where such need was identified. This stage finished with confirmation by the employee in charge of the division made in the list that the system was put into operation in his division and that the final version of the documentation for his division was approved without remarks or need of updating.

\subsection{Stage 4. Maintenance, Performance and Control}

(1) Providing the necessary resources. Providing the necessary resources for the introduction, maintenance and continuous improvement of IMS shall be the obligation of the top management of the organization. Providing the necessary resources is the main prerequisite for meeting customer requirements for conformity and safety of foodstuffs. The possibilities and the limitations of the internal resources, as well as the feasibility and the challenges in making use of external suppliers, shall be determined in the processes of resource management. It was established that the need and requirements for resources shall be determined by the management in the Review of IMS.

(2) Application of controls for the achievement of target quality and safety. We carried out systematic observation and control of the products in each step of the technological process. The information from the systematic observation made it possible to assess if the introduced controls operated as designed and if the hazards were reduced to the defined acceptable levels. It was established that the measuring equipment was suitable calibrated and allowed to make the tests in a way that is compatible with the requirements for measuring.

(3) Operations management for achievement of target quality. The company where the system has been introduced can guarantee that it has created all necessary conditions to meet the customer requirements. The company exercises with due diligence resources owned by customers, while they 
PIMS 820 Trade management and information exchange with customers. Customer focus and communication (cl.8.2.)

Specific requirements of customers for raw materials and processes

\section{PIMS 840 control of} externally provided products and services (cl.8.4.) PP - 03 Input control and storage of products, laboratory analysis (cl.8.4.)

\section{PP - 02 Transport \\ PP - 08 Pest Control \\ PP - 07 Waste Management PP 09 Management of allergen and GMO}

PP 01 Equipment and utilities PP 04 Housekeeping and hygiene

PP 05 Personal hygiene PP 06 Chemical and physical product contamination control

PIMS 810 Operational planning and control (cl.8.1.) PIMS 712 Human and Financial Resource (cl.7.1.) PIMS 713 Infrastructure (cl.7.1.) PIMS 715 Monitoring and Measuring Resources (cl.7.1.) PIMS

720 Competence (cl.7.1.)

Evidence of compliance with the acceptance criteria and agreement. Certificate or declaration of product authenticity, claims and chain of custody

\section{PIMS 930 Management review. Context of the organization. Leadership. Aims and objectives. Planning change (cl.6.1.) \\ PIMS 750 Document management}

PIMS 610 Actions to address the risks and opportunities. Customer feedback determining a customer's needs, tastes and requirements

Preparing assortment list. Producing and submitting the offer to clients. Contract for delivery.

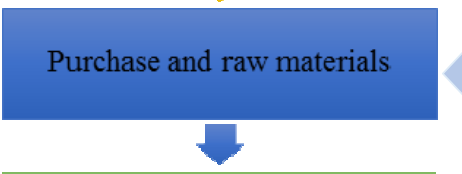

Receipt and acceptance pursuant to specifications

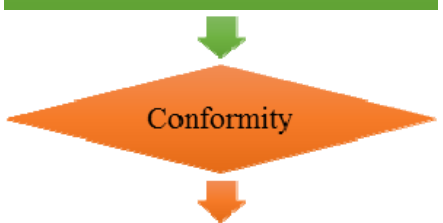

Using the supply or the raw material in the manufacturing processes

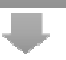

Confirmation and monitoring of process compliance

Final inspection

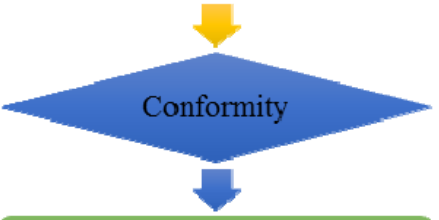

Packaging, product labelling Quantity - weight, volume and number control

\section{Storage and dispatch}

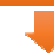

Delivery activities

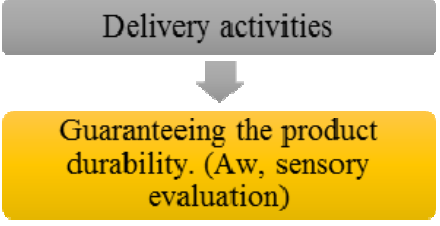

PIMS 610-02 Food defense ons Actions to address the crises and emergencies, (cl.6.1.) PIMS 610-03 Preliminary steps to enable hazard analysis (cl.6.1.) PIMS 610- 04 Hazard Analysis (cl.6.1.) PIMS 610-05 Establishing the HACCP plan (cl.6.1.)

PIMS 830 Design and development of products (cl.8.3.)

Type and extent of control of external. Preservation.

Inspection, analysis, certificate, declaration, Aw, sensory evaluation

\section{Return of supplier,} scrapping, destruction

PIMS 850 Production and service provision(cl.8.5.) PIMS 852 Identification and traceability(cl.8.5.2.)

PIMS 910 Monitoring, measurement, analysis (cl.9.1.) PIMS 920 Internal audit (cl.9.2.) PIMS 1020 Nonconformity corrective action (cl.7.1.)

Rework, Recycle and Reprocess

PIMS 854-01 Protection, packaging and storage of inputs (cl.8.5.) PIMS 854-02 Inspection of packaged quantities PIMS 860 Inspection and testing, (cl.8.6.) PIMS 870 Control of nonconforming (cl.8.7.)

Inspection, analysis, AW, sensory evaluation

Fig. 3 IMS process model-sequence and interaction of processes. 
are under the control of the organization or have to be used. We have entered in contractual relations for control, storage, maintenance and reporting customer property granted to the company for carrying out operations related to performance. The organization has a regulation to confirm the customer requirements before accepting them, when the customer has not submitted them documented in writing.

(4) Management of resources and documented information. A special procedure IMS 750-01 was set up, which regulates the rules for development, identification, inspection, approval and distribution, updating and storage of documented information in IMS. The procedure defines the form and the content of the IMS documents and regulates the employment of a unified approach in document creating and management. The application of this procedure creates prerequisites to work only with valid and documented information everywhere in the organization, and to apply a unified approach in the development and management of the documents for the system.

The documented information which has been determined as necessary for the IMS efficiency includes: policy and objectives for food quality and safety, IMS Manual, ISP (integrated system procedures), PP (prerequisite programs); Operating instructions, documents of external origin, records; IMS forms.

(5) Process management for achievement of quality and safety. We defined the necessary and sufficient processes to meet the requirements for conformity of the offered products and services, and to carry out actions for minimizing the risks. Planning of operating processes includes determining the purpose of product and its envisaged use, the processes necessary for its manufacturing and delivery, and creating programs for verification of the quality and safety of the manufactured product. The plan created by us included defining the records necessary to prove the conformity of process and product. We made it a rule to carry out operating planning also before introducing new products or processes, as well as in case of substantial improvements of existing conditions and operations.

\subsection{Stage 5. Performance Assessment}

We determined specific sites to be observed, measured, analyzed and assessed: criteria, processes, product specifications, applied methods for risk and quality management. We agreed to carry out monitoring and measurements in compliance with IMS, the instructions for the process and the adopted methods for work. It was established that the monitoring results, the measurements and the assessment were analyzed and valuated. It was established that information reports from the analyses were submitted for Management Review, in order to take decision as to the possibilities for improvement, need for changes and need for resources.

(1) Monitoring measuring of quality and safety indication. It was established that the company analyzed and assessed the respective data and information, obtained as result of observation and measuring.

(2) Internal audit. It was established that the audits already carried out allowed following a better efficiency of the system. The internal and external audits were used as source of information to take account of the overall effect from the model implementation and to trace the possible results for the achievement of better management and sustainability of processes. An IMS procedure was introduced to regulate the methodology, interactions and the document flow in carrying out internal audits.

We established Procedure IMS $870-01$ for the management of non-conformities and corrective actions. The procedure rules that in the event of non-conformity, a plan shall be worked out with corrective actions for eliminating the non-conformity and its reason, to minimize the risk or to prevent the possibility of recurrence. The introduction of the procedure regulates the necessary control in the 
management of products, processes and services not conforming to the specification. In cases where the process is beyond the critical limits at critical control points, the affected end products shall be identified in a suitable manner and their movement, use and placement shall be controlled.

(3) Review by the management. The top management carried out a review in order to establish the IMS efficiency, its continuous employability, adequacy and compliance with the strategic orientation of the company.

(4) Conformity assessment by an accredited body. The certification of the system according to the applied model confirms its compliance with the legislative requirements and the standards applicable to the system.

The Certificate of Conformity can be used as evidence before trade and other counterparties that the company has implemented a certified system for securing food quality and safety. The conformity of the introduced system according to the applied model was assessed in May and September 2016 by an accredited body for conformity assessment of food quality and safety systems. The certificates issued on the basis of an audit report by a third party for the system introduced under the model in this research confirm the conformity of the system with ISO 9001:2015, ISO 22 000:2006; BRC Food 7 at 98.5\%, and IFS Food 6 at $97.6 \%$.

\subsection{Stage 6. Completion of the Project for the Implementation of the Model}

(1) Project performance assessment. It was established that the planned project objectives for the implementation of the system were achieved and the results from the conformity given by the accredited body were also taken into account. The conclusions from the analysis can be used in future modeling of systems.

(2) Conformity assessment in accordance with planned activities. The conformity assessment established the appropriateness, effectiveness, efficiency and sustainability of the model applied for integration. The relevant assessment report included the presentation of evidence for the positive result achieved and considered the causal connection between the executed activities.

(3) Submission of report on completing the implementation of the model. Following the preparation of the project documentation, we submitted a report on the project performance concerning the planning and implementation of IMS. The report on completing the implementation of the model into practice included conclusions that the project was completed in time and in compliance with the agreed action plan.

\subsection{Stage 7. Improvement}

Continuous improvement: We identified criteria for the continuous improvement of the model in practice by using operational indicators, in order to make possible evaluating the achieved success. The identified indicators were: degree of customer satisfaction/dissatisfaction, increase or decrease of selling units, increase or decrease of defects per million sold units and many others.

It is planned that the system will maintain Procedure IMS 870-01 with the aim of continuous improvement and efficiency of IMS in accordance with the legislative and international standards and the best practices in the industry.

\section{Discussion}

The application of integrated systems is an important condition, which guarantees minimizing the risk of manufacturing products not conforming to the legislative requirements and the specification. Meeting the main challenges related to increasing the customer satisfaction, requires creating the necessary conditions for developing and improving the management of manufacturing products, in order to achieve sustainable compliance with the requirements. 
Meeting the challenges linked to the technological fields, which are related with the interest of both consumers and producers, gives the necessary impulse for the successful application and use of the integrated processes and action procedures.

As result of introducing the integrated system, the negative impact of the risk factors can be eliminated or reduced in accordance with the principles for quality management and safety of biscuit products.

It was established that the conformity reports by the accredited body confirmed the following achieved benefits from the introduction of system according to the model proposed in this presentation:

- Opening up of new opportunities for entering new markets, where the certificates of conformity are a necessary condition for business with the big trade chains;

- Ensuring compliance with the legislative and other requirements related to food safety and quality.

- Achieving a unified approach of conformity management in accordance with the requirements of several standards related to food safety and quality.

These advantages confirm the conclusions made in scientific publications - in a number of researches of integrated systems, which are not based on the revised version of the quality management standard ISO 9001:2015 [7-14].

However, the introduction of integrated management models should observe also certain restrictive conditions. These conditions will allow minimizing the negative effects such systems may have with respect to processing a large amount of information, which has to be integrated, as well as the higher costs related to certification and purchasing of new equipment.

The model of designing and introduction of the quality management system was applied under the following restrictive conditions:

- The integrated quality management system was developed in accordance with the requirements of the standard ISO 9001:2015.

- The proposed model for planning and implementation is intended for the enterprises, which apply management systems in accordance with the four standards: ISO 9001; ISO 22 000; IFS Food 6 and BRC Food 7.

- The direct transfer to other enterprises which do not meet the above conditions, without being adapted to their specific circumstances, cannot guarantee correctness of the results obtained.

- Although each process in manufacturing a biscuit product seems the same and often covers similar processes, each organization and its quality management system is unique.

- Regardless of the planned measures for the neutralization of the most frequently occurring external and internal factors, which might distort the obtained results, the methodology developed is unable to eliminate the impact of all random factors.

- It is impossible to identify in advance all systems, processes and activities; therefore, it is essential for the model to be flexible and adaptable, in order to respond to the increasing complexity of the context of the respective organization.

- The performance assessment for the model can be used in decision making or in identifying improvements of the methodology for its implementation. The assessment report includes comprehensive analysis and the contributions resulting from the implementation of the model of quality and safety management system.

\section{Conclusions}

The implementation of a model of integrated quality and safety management for biscuit products can create the necessary and sufficient conditions for meeting the requirements for conformity according to ISO 9001:2015; ISO 22 000:2005; IFS Food 6 and BRC Food 7. Sustainability was achieved by using the integrated approach to the various requirements of the standards on the basis of the synergetic effect between 
the interrelated manufacturing processes. The conformity audits carried out by an accredited body confirmed that regardless of the many risks from the internal environment and the many increasingly burdensome requirements of the internationally recognized standards, the developed integrated management system was found to be in conformity.

The introduction of the model for integrated management system can be important for the biscuit manufacturers, supporting them efficiently to address challenges such as limited resources, increasing competition and the higher expectations of customers and other stakeholders.

\section{References}

[1] Garengo, P., and Stefano, B. 2012. "From ISO Quality Standards to an Integrated Management System: An Implementation Process in SME." Total Quality Management \& Business Excellence 24 (3-4): 310-35.

[2] Zeng, S., Xie, X., Tam, C., and Shen, L. 2011. "An Empirical Examination of Benefits from Implementing Integrated Management Systems (IMS).” Total Quality Management \& Business Excellence 22 (2): 173-86.

[3] Miguel, R., Searcy, C., and Karapetrovic, S., 2007. "Integrating Sustainable Development into Existing Management Systems." Total Quality Management \& Business Excellence 18 (1-2): 83-92.

[4] International Organization for Standardization. 2015. ISO 9001:2015 Quality Management Systems-Requirements, Genève: ISO.

[5] IFS Management. 2014. IFS Standard for Auditing Quality and Food Safety of Food Products Version 6. Berlin: IFS Management GmbH.

[6] British Retail Consortium. 2015. BRC Global Standard Food Safety Issue 7. London: British Retail Consortium.

[7] International Organization for Standardization. 2005. ISO22000, Food Safety Management SystemsRequirements for Any Organization in the Food Chain. Genève: ISO.

[8] Zeng, S., Xie, X., Tam, C., and Shen, L.2011. “An Empirical Examination of Benefits from Implementing Integrated Management Systems (IMS).” Total Quality Management 22 (2): 173-86.

[9] Fulponi, L. 2006. "Private Voluntary Standards in The Food System: The Perspective of Major Food Retailers in OECD Countrie." Food Policy 31 (1): 1-13.

[10] Mainville, D. Y., Zylbersztajn, D., Farina, E. M., and Reardon, T. 2005. 'Determinants of Retailers' Decisions to Use Public or Private Grades and Standards: Evidence from the Fresh Produce Market of São Paulo, Brazil." Food Policy 30 (3): 334-53.

[11] Henson, S. 2008. "The Role of Public and Private Standards in Regulating International Food Markets." Journal of International Agricultural Trade and Development 4 (1): 63-81.

[12] Manning, L., and Baines, R. 2004. "Effective Management of Food Safety and Quality." British Food Journal 106 (8): 598-606.

[13] Henson, S., and Humphrey, J. 2009. "The Impacts of Private Food Safety Standards on the Food Chain and on Public Standard-Setting Processes." Joint FAO/WHO Food Standards Programme, Codex Alimentarius Commission, Thirty-second Session. Rome: FAO Headquarters.

[14] Henson, S., and Hooker, N. H. 2001. "Private Sector Management of Food Safety: Public Regulation and the Role of Private Controls." Food and Agribusiness Management Review 4 (1): 7-17.

[15] Karapetrović, S., Edmonton, A., Casadesus, M., and Heras , I. 2010. "Tegration within the Standards-based Integrated Management Systems." International Journal for Quality Research 4 (1): 25-35.

[16] Karapetrovic,S. 2003. "Musings on Integrated Anagement Systems." Measuring business excellence 7 (1): 4-13.

[17] Henson, S., and Reardon, T. 2005. "Private Agri-Food Standards: Implications for Food Policy and the Agri-Food System." Food Policy 30 (3): 241-53.

[18] Hobbs, J., Fearne, A., and Spriggs, J. 2002. "Incentive Structures for Food Safety and Quality Assurance: An International Comparison." Food Control 13 (2): 77-81.

[19] Henson, S., Masakure, O., and Boselie, D. 2005. "Private Food Safety and Quality Standards for Fresh Produce Exporters." Food Policy 30 (4): 371-84.

[20] Karaman, A., Cobanoglu, F., and Tunalioglu, R. 2012. "Barriers and Benefits of the Implementation of Food Safety Management Systems among the Turkish Dairy Industry: A Case Study." Food Control 25 (2): 732-9.

[21] Trienekens, J., and Zuurbier, P. 2008."Quality and Safety Standards in the Food Industry, Developments and Challenges." International Journal of Production Economics 113 (1): 107-22.

[22] Martinez, M., and Poole, N. 2004. "The Development of Private Fresh Produce Safety Standards: Implications for Developing Mediterranean Exporting Countries." Food Policy 29 (3): 229-55.

[23] Reardon, T., and Farina, E. 2001. "The Rise of Private Food Quality and Safety Standards: Illustrations From Brazil." The International Food and Agribusiness Management Review 4 (4): 413-21. 
[24] Jaffee, S., and Masakure, O. 2005. "Strategic Use of Private Standards to Enhance International Competitiveness: Vegetable Exports from Kenya and Elsewhere." Food Policy 30 (3): 316-33.

[25] Santos, G., Mendes, F., and Barbosa, J. 2011. "Certification and Integration of Management Systems: the Experience of Portuguese Small and Medium Enterprises." Journal of Cleaner Production 19 (17): 1965-74.

[26] British Standards Institution. 2012. PAS 99:2012 Specification of Common Management System Requirements as a Framework for Integration. 1st ed. London: British Standards Institution.

[27] Patton, M. Q. 1987. How to Use Qualitative Methods in Evaluation. 4th ed. Thousand, California: Sage. 